\title{
CONTRADIÇÕES DO IDEÁRIO NEOLIBERAL NA POLÍTICA DE ASSISTÊNCIA ESTUDANTIL: DO NASCEDOURO AOS DIAS ATUAIS
}

\section{CONTRADICTIONS OF THE NEOLIBERAL IDEARY IN THE STUDENT ASSISTANCE POLICY: FROM BIRTHDAY TO CURRENT DAYS}

\section{CONTRADICCIONES DEL IDEARIO NEOLIBERAL EN LA POLÍTICA DE ASISTENCIA ESTUDIANTIL: DEL CUMPLEAÑOS A LOS DÍAS ACTUALES}

\author{
Marília do Amparo Alves Gomes ${ }^{1}$ \\ Ennia Débora Passos Braga Pires ${ }^{2}$ \\ Soane Santos Silva ${ }^{3}$
}

Resumo: $\mathrm{O}$ artigo busca resgatar e discutir a trajetória histórica da política de Assistência Estudantil ( $A E$ ) que tem como finalidade fomentar o acesso e a permanência de jovens das classes populares à universidade. Como uma política pública inserida no contexto do capitalismo, a Assistência Estudantil é forjada em meio a contradições, por um lado atende parcialmente as reivindicações da classe trabalhadora, por outro, apresenta aspectos minimalistas característicos das políticas focais. Conclui apontando que a $A E$, em nível nacional, com o Programa Nacional de Assistência Estudantil (PNAES), atende rigorosamente ao receituário neoliberal e as orientações dos organismos multilaterais para a educação no Brasil.

Palavras-Chave: Assistência Estudantil. Ensino Superior. Política Educacional.

Abstract: The article seeks to discuss the historical trajectory of the Student Assistance (AE) policy that aims to promote access and permanence of young people from the lower classes to the university. As a public policy inserted in the context of capitalism, Student Assistance is forged amid contradictions, on the one hand it partially meets the demands of the working

\footnotetext{
${ }^{1}$ Universidade Estadual do Sudoeste da Bahia. Vitória da Conquista, Bahia, Brasil.

${ }^{2}$ Universidade Estadual do Sudoeste da Bahia. Vitória da Conquista, Bahia, Brasil.

${ }^{3}$ Universidade Estadual do Sudoeste da Bahia. Vitória da Conquista, Bahia, Brasil.
} 
class, on the other, it presents minimalist aspects characteristic of focal policies. He concludes by pointing out that $A E$, at the national level, with the National Student Assistance Program (PNAES), strictly complies with the neoliberal prescription and the guidelines of multilateral organizations for education in Brazil.

Keywords: Student Assistance. Higher Education. Educational Politics.

Resumen: El artículo busca rescatar y discutir la trayectoria histórica de la política de Asistencia Estudiantil (AE) que tiene como objetivo promover el acceso y la permanencia de los jóvenes de las clases bajas a la universidad. Como una política pública insertada en el contexto del capitalismo, la Asistencia Estudiantil se forja en medio de contradicciones, por un lado, cumple parcialmente con las demandas de la clase trabajadora, por otro, presenta aspectos minimalistas característicos de las políticas centrales. Concluye señalando que $A E, a$ nivel nacional, con el Programa Nacional de Asistencia al Estudiante (PNAES), cumple estrictamente con la prescripción neoliberal y las directrices de las organizaciones multilaterales para la educación en Brasil.

Palabras clave: Asistencia al Estudiante. Enseñanza Superior. Política Educativa.

\section{INTRODUÇÃO}

Uma análise sobre políticas públicas educacionais deve considerar que a pobreza e as desigualdades sociais não se dão de forma natural. Assim, partindo de uma perspectiva que entende as desigualdades presentes na política pública de educação como parte das contradições próprias de uma sociedade capitalista baseada na exploração e na opressão, é possível identificar algumas das expressões da questão social ${ }^{4}$ articuladas à realidade atual.

É importante demarcarmos o surgimento da política de Educação Superior no Brasil e, posteriormente, da política de assistência estudantil como expressão de uma ampla junção de interesses, embates e reivindicações. Partimos do pressuposto de que a existência de grupos populares crescentes que permanecem privados do direito ao acesso ao Ensino Superior e do acesso ao trabalho compõe uma dimensão estrutural do capitalismo. Percebemos, portanto, que não se trata de um fenômeno próprio de contextos espaciais

\footnotetext{
4 Esta expressão começou a ser utilizada a partir do século XIX e "[...] surge para dar conta do fenômeno mais evidente da história da Europa Ocidental que experimentava os impactos da primeira onda industrializante, iniciada na Inglaterra no último quartel do século XVIII: trata-se do fenômeno do pauperismo. Com efeito, a pauperização massiva da população trabalhadora constituiu o aspecto mais imediato da instauração do capitalismo em seu estágio industrial-concorrencial” (NETTO, 2011, p. 152-153).
} 
específicos, mas sim, de implicações da histórica desigualdade própria do sistema de produção nas sociedades capitalistas.

Em todas as fases, o capitalismo objetivou a imposição de ideologias que naturalizassem a dominação de uma elite privilegiada sobre a população empobrecida, por isso não é possível pensar nesse sistema sem considerar o antagonismo de classes. Como enfatiza Netto (2012), o capitalismo só deu certo para os proprietários dos meios de produção, haja vista que esse modo de produção expressa relação direta com a questão social.

Marx e Engels já denunciavam a desigualdade de classe no capitalismo na primeira frase do Panfleto Manifesto Comunista escrito em 1848, quando lembravam que se na sociedade feudal existiam muitas classes, na sociedade burguesa, no capitalismo, são identificadas novas formas de opressão e de lutas, sendo a sociedade dividida cada vez mais em dois vastos campos opostos: a burguesia e o proletariado (MARX; ENGELS, 2011).

A partir da década de 1970, com a crise estrutural do capital, a elite mundial preocupada em manter privilégios e garantir a preservação do sistema adota o ideário neoliberal, novo modelo de política e controle que tem seu marco em 1989 quando ocorre o Consenso de Washington, caracterizado por um conjunto de regras econômicas acordadas por economistas de grandes instituições financeiras que passaria a orientar a elaboração das políticas econômicas e sociais recomendadas por grandes organismos internacionais, tais como: Fundo Monetário Internacional (FMI), Banco Mundial (BM), Banco Internacional para Reconstrução e Desenvolvimento (BIRD) e o Banco Interamericano de Desenvolvimento (BID).

Estas instituições formulam orientações que são seguidas rigorosamente pelos países que requerem "empréstimos" e, como contrapartida, têm nas exigências os ditames do neoliberalismo, os ajustes econômicos e, principalmente, políticas cada vez menos impactantes na realidade social.

No Brasil, a partir da década de 1990 é possível perceber claramente traços desse ideário como a minimização do Estado e a garantia do livre mercado. A realidade brasileira é marcada por governos que historicamente têm feito opções políticas que sobrepõem o pagamento da dívida pública brasileira em detrimento do investimento em políticas sociais que poderiam causar grande impacto nos problemas sociais do país. Neste sentido, Peroni (2003) enfatiza que o Estado tem se apresentado como mínimo para as políticas sociais e, em compensação, máximo para o capital. 
Com isso, o aprofundamento das desigualdades se dá a partir da materialização dos ideários neoliberais que se baseiam na retirada do Estado da economia, aparece aqui a ideia do Estado Mínimo, a volta das leis de mercado sem restrições, o aumento da taxa de juros para ampliar o consumo, a diminuição dos impostos sobre o capital e diminuição dos gastos públicos, e, consequentemente, dos investimentos em políticas sociais. Com o neoliberalismo, elimina-se a possibilidade de concretização do Estado de Bem-Estar Social, incentivando severos cortes nos gastos sociais ${ }^{5}$.

Esses cortes se dão majoritariamente nas políticas sociais, dentre elas, na política de educação incluindo as políticas de assistência estudantil. Nessa problematização, questionamos como foi construída a trajetória da política de assistência estudantil, a qual se constitui como essencial para os estudantes em situação de vulnerabilidade social e quais os atores envolvidos na construção desta política.

Compreendemos que a partir das análises das políticas públicas, os atores sociais podem reivindicar mudanças. No entanto, é necessário chamar atenção para o fato de que, quando inseridas no modo de produção capitalista, essas políticas não têm alcance nas estruturas das desigualdades. No momento atual do desenvolvimento capitalista se dá o aprofundamento da barbárie, isso explica o fato das políticas públicas no contexto neoliberal apenas amenizarem os efeitos da pobreza e não atuarem com o objetivo de eliminá-la (NETTO, 2012).

Nesse sentido, uma análise das políticas públicas sociais na atualidade nos permite argumentar que os programas sociais, por exemplo, deveriam estar aliados às transformações estruturais na sociedade, pois, assim teriam impacto profundo, mas, ao contrário, são programas emergenciais e basicamente assistencialistas.

[...] a política social dirigida agora aos qualificados como excluídos se perfila reivindicando-se sempre como inscrita no domínio do direito, enquanto específica do capitalismo, ela não tem nem mesmo a pretensão formal de erradicar a pobreza, mas de enfrentar apenas a penúria mais extrema a indigência, conforme seu próprio discurso pretende confrontar-se com a pobreza absoluta, vale dizer a miséria. (Netto, 2012, p. 28)

\footnotetext{
5 O Estado do Bem-estar surgiu após a Segunda Guerra Mundial. Seu desenvolvimento está relacionado ao processo de industrialização e os problemas sociais gerados a partir dele. Ocorreu também uma vertiginosa ampliação dos serviços assistenciais públicos nas áreas de renda, habitação e previdência social, entre outras.
} 
Seguindo o mesmo viés, a política de educação no Brasil sempre esteve restrita aos interesses da elite brasileira. Segundo Motta (2008. p. 04), a relação pobreza e educação foi estabelecida "desde a formação das sociedades capitalistas como mecanismo de estabilidade política, com proposta de conter possibilidades de ruptura da coesão social e instaurar a ordem necessária à reprodução do capital”, mas também pode ser um fator de superação das condições de pobreza da classe trabalhadora. Vale lembrar que a classe trabalhadora e as camadas populares enxergam na educação uma possibilidade de ascensão social e de libertação de modelos de escravização próprios do modo de produção capitalista.

\section{POLÍTICA DE ASSISTÊNCIA ESTUDANTIL NA EDUCAÇÃO SUPERIOR}

Estudiosos apresentam diferentes experiências para explicar a instituição da educação superior no Brasil. Nesta análise, tomaremos como referência o pensamento de Saviani (2010, p. 06) que refere que "os cursos superiores propriamente ditos começaram a ser instalados no Brasil a partir de 1808, com a chegada de D. João VI. Surgiram, então (...) cursos superiores isolados, isto é, não articulados no âmbito de universidades", portanto, esta é a gênese do ensino superior brasileiro.

No que concerne à assistência estudantil (AE) no Brasil, Kowalski (2012) sinaliza que sua origem está atrelada ao nascimento da universidade e se transforma juntamente com toda a história da Educação Superior brasileira, marcada por um contexto social em constante processo de movimento, com descaminhos até a legitimação dos programas de AE. A seguir, tomando como referência a pesquisa de Kowalski (2012), apresentamos a trajetória histórica da assistência estudantil no contexto brasileiro, evidenciando as contradições ao longo do percurso tomando como referência o quadro histórico da AE no Brasil.

\subsection{PRIMEIRA FASE DA ASSISTÊNCIA ESTUDANTIL NO BRASIL}

Na primeira fase as ações de assistência ao estudante são datadas a partir de 1928, com a criação da residência universitária destinada aos jovens que se dirigiam à França para estudar e tinham dificuldades de fixar moradia no país, cabendo ao governo brasileiro o repasse de recursos tanto para a edificação das estruturas como para manutenção da casa e dos estudantes. Contudo, devemos destacar que a assistência estudantil, nesse período 
histórico, estava restrita ao atendimento das necessidades dos filhos da elite brasileira, já que só esses tinham acesso ao Ensino Superior, ratificando que a desigualdade no acesso, tem relação direta com desigualdade social.

É importante ressaltar que as bases das lutas estudantis na América Latina foram influenciadas pela Reforma de Córdoba. Dezenas de estudantes ocuparam a sede da Universidade Nacional de Córdoba, na Argentina. O movimento estudantil cordobês lançou em 21 de junho de 1918 o Manifesto denominado "Da juventude argentina de Córdoba aos homens livres da América", no qual descrevem de forma contundente a realidade universitária. Segundo Freitas Neto (2011), após emissão de carta pastoral do Bispo de Córdoba na qual condenava a mobilização estudantil, no mês de julho de 1918, os estudantes realizaram o I Congresso Nacional de Estudantes Argentinos e reforçaram as reivindicações do Manifesto, sintetizando como principais pautas: coparticipação dos estudantes na estrutura administrativa; participação livre nas aulas; periodicidade definida e professorado livre das cátedras; caráter público das sessões e instâncias administrativas; extensão da Universidade para além dos seus limites e difusão da cultura universitária; assistência social aos estudantes; autonomia universitária; universidade aberta ao povo.

Em 09 de setembro do mesmo ano, os estudantes tomaram a direção e o controle da Universidade e reabriram a instituição, o governo designou como interventor José Salinas que contou com apoio dos estudantes, foi publicado Decreto que respondia as reivindicações, assegurando o triunfo do Movimento. Houve repercussão dos ideais do Movimento em toda América Latina, ainda que tardiamente no Brasil, especialmente, pelas especificidades da história do ensino superior no país.

No que concerne à prática de assistência estudantil em solo brasileiro, ainda que tenham registros de ações isoladas anteriores, tem como marco a construção da primeira Casa do Estudante no ano de 1930 no Rio de Janeiro, durante o governo de Getúlio Vargas; por interesse do governo foram concedidas doações. Posteriormente, a Casa passou a ser uma entidade de auxílio aos estudantes sem conotações políticas, onde abrigava diversos serviços destinados a estudantes carentes, como: restaurante popular, residência estudantil, biblioteca, entre outros. Após 1937, a Casa do Estudante tornou-se sede administrativa da União Nacional dos Estudantes (UNE) que passou a ter controle dos serviços de assistência aos estudantes oferecidos no local (VASCONCELOS, 2010). 
Em todo percurso da Educação Superior percebemos os focos de resistência ao modelo de Universidade apresentado pela elite. O movimento estudantil (ME) através da UNE é um dos atores importantes na luta pela $A E$ e pautou, dentre as reivindicações, um olhar para acesso e permanência no Ensino Superior. Kowalski (2012) ressalta que o Ministério da Educação apoiou a criação da UNE como uma estratégia do governo de construir uma instituição despolitizada, com sede administrativa na Casa do Estudante do Brasil responsável em promover a assistência jurídica, bolsas, empregos, biblioteca, saúde e residência.

As reivindicações da UNE se intensificam especialmente na temática concernente a reforma universitária e aos direitos para os estudantes da educação superior. Já em 1961, a UNE realiza, em Salvador, o Seminário Nacional de Reforma Universitária que resultou na Declaração da Bahia que reivindicava o pluralismo nas universidades, com cursos acessíveis (KOWALSKI, 2012). Além disso, trazia discussões sobre questões políticas nacionais e os problemas da reforma da sociedade. No mesmo ano foi promulgada a LDB de 1961 que estabelecia a assistência estudantil como um direito que deveria ser garantido de forma igual a todos os estudantes com previsão de assistência social, médico-odontológico e de enfermagem aos alunos, além da oferta de bolsas gratuitas aos educandos para custeio total ou parcial dos estudos, com financiamento para reembolso no prazo de quinze anos.

Apesar das reivindicações pontuais, a reforma universitária se constituía como bandeira da UNE com objetivo principal de tornar a universidade um espaço pluralizado com acesso garantido a todos. Esta entidade tem papel basilar na construção da $A E$, especialmente a partir do período da Ditadura Militar, pois, nesta época a UNE sofreu fortes represálias devido às manifestações.

Dentre os dezessete decretos emitidos pela ditadura militar nos anos que se seguiram ao golpe de estado de 1964 no Brasil, o Ato Institucional Número Cinco (Al-5) foi o mais duro de todos eles, foi emitido pelo presidente Artur da Costa e Silva em 13 de dezembro de 1968. Este Decreto apresentou como resultado a perda de mandatos de parlamentares opositores aos militares, além de intervenções ordenadas pelo presidente nos municípios e estados e também na suspensão de garantias constitucionais que resultaram na institucionalização da tortura, usada como instrumento pelo Estado.

Porém, como uma contradição, o período militar a partir de 1964, por um lado repreende fortemente o movimento estudantil, por outro lado, cria a falsa ideia de igualdade 
de oportunidades. Dessa forma, evidencia-se, durante os governos militares, um processo ilusório de inclusão das camadas mais populares. Os estudantes estavam organizados em diversas entidades representativas, como os Diretórios Centrais Estudantis (DCEs), as Uniões Estaduais dos Estudantes (UEEs), além da União Nacional dos Estudantes (UNE) e suas reivindicações, protestos e manifestações tinham como pautas as questões políticas do país.

Uma das motivações das reivindicações nas ruas era o questionamento acerca dos "excedentes", estudantes que obtinham média nos vestibulares, mas não ingressavam na Universidade porque o número de vagas era inferior ao número de aprovados (ANTUNES; RIDENTE, 2007). Revoltados com essa realidade, em 28 de março de 1968, os estudantes, em sua maioria, secundaristas pobres se mobilizaram no restaurante estudantil no Rio de Janeiro, denominado Calabouço; a polícia invadiu o restaurante, gerando o primeiro grande conflito de rua daquele ano. Muitos estudantes ficaram feridos e o secundarista Edson Luís de Lima Souto foi morto.

As repercussões desse conflito geraram outra grande mobilização contra o regime militar com greve geral decretada pela UNE, com apoio de sindicalistas, artistas, religiosos e intelectuais ao movimento que culminou, em junho do mesmo ano, na passeata dos Cem Mil no Rio de Janeiro, pedindo democracia, liberdade e justiça; tal ato marcou a história da resistência do Brasil.

Ainda no mês de junho 1968, ocorreram passeatas, greves e ocupações de faculdades, com foco principal no Rio de Janeiro; em resposta a isso, os atos de repressão eram cada vez mais duros. Antunes e Ridente (2007) destacam que no dia 21 de junho, no protesto que posteriormente ficou conhecido como "sexta-feira sangrenta", quatro pessoas foram mortas, além de dezenas feridas e centenas presas. Com o cenário marcado pela repressão, os militantes do movimento estudantil eram perseguidos, postos na ilegalidade e/ou mortos.

Neste sentido, uma estratégia comum dos líderes do poder era a invisibilização da luta de classes, para isso desarticulava-se a classe trabalhadora. A propagação de conflitos entre os estudantes de posicionamentos ideológicos antagônicos, por exemplo, é uma tentativa de enfraquecimento do $\mathrm{ME}$, além de buscar conquistar com êxito o objetivo de capturar as lideranças do movimento, sem repercussões negativas do regime militar perante a sociedade. Ao contrário, os episódios de violência explícita dos militares contra os estudantes fizeram 
com que a população tomasse as ruas em defesa destes, mas com o aumento da repressão eles se mantinham articulados com objetivo de organizar o Congresso da UNE.

Como mais um ato extremo de violência dos militares, em 15 de outubro, no Congresso da UNE, em Ibiúna, no Estado de São Paulo, todos participantes foram presos, cerca de mil estudantes, conforme informação do site da UNE (2018), marcando assim o fim dos protestos de 1968, pois, no fim do mesmo ano é proclamado o Ato Institucional número cinco (AI-5) indicando, ainda, maior repressão aos opositores do regime militar. A partir de então vários integrantes do ME passariam a militância política clandestina. Somente ao final de 1970, o ME começou a se reestruturar a partir do Congresso da UNE.

Apesar do histórico de violência contra o ME percebe-se como avanço na década de 1970, conforme aponta Vasconcelos (2010), a instituição do Departamento de Apoio ao Estudante (DAE) vinculado ao Ministério da Educação (MEC). O Departamento era responsável por manter uma política de assistência ao estudante universitário em nível nacional, com prioridade para os programas de alimentação, moradia, assistência médica e odontológica. Porém, os governos posteriores deram pouca importância à assistência estudantil extinguindo O DAE.

Isso evidencia que a implementação de políticas de curta duração depende da estratégia política de governos e conjuntura para permanecerem. Nesse caso, a instituição do DAE, com ações voltadas para permanência estudantil, em um período de grande repressão aos estudantes, não deve ser entendida como uma benesse do governo, mas sim como uma tentativa de conter o $\mathrm{ME}$, a partir de duas estratégias: a repressão concreta com mortes e prisões de estudantes e a aparência de atendimento das demandas estudantis.

O contexto mundial da década de 1970 foi marcado pelo despontar das ideias neoliberais se estabelecendo no Brasil na década de 1990. Frigotto (2010) afirma que o ideário neoliberal e neoconservador se tornou a palavra de ordem para o ajustamento e submissão às regras dos novos senhores do mundo e suas instituições tanto nos países da América Latina quanto para países do leste europeu.

As lutas do ME se davam em direção contrária a lógica do capital, especialmente a luta por uma política de permanência que na década de 1970 foi liderada também pelo Movimento de Casas de Estudante (MCE), pois, o movimento estudantil sempre teve uma ligação muito forte com as moradias estudantis, o que ganhou ênfase na década de 1970, sendo que a partir 
de 1975 passa a promover o Encontro Nacional de Casas de Estudantes. Tal encontro é a instância máxima de deliberação da Secretaria Nacional de Casas de Estudantes (SENCE). No evento os estudantes residentes se organizam por meio de mobilizações em busca de melhorias em suas moradias, também por assistência estudantil e por justiça social. O site da SENCE destaca como características principais do Movimento de Casas de Estudantes (MCE) o seu caráter de resistência e a dispersão pelo país, uma vez que traz um histórico de lutas e está presente nas várias regiões do Brasil com discussões sobre AE e de forma específica sobre a situação da moradia estudantil.

\subsection{SEGUNDA FASE DA ASSISTÊNCIA ESTUDANTIL NO BRASIL}

Kowalski (2012, p. 101) sinaliza que a segunda fase de implementação da AE se dá a partir da democratização política do Brasil, com a qual "[...] há um espaço propício para uma série de debates e projetos de leis que resultaram em uma nova configuração da $A E$ nas universidades brasileiras", portanto, destacam-se outros atores importantes que, juntamente com o ME, contribuíram sobremaneira para a construção de uma AE. A exemplo da criação do Fórum Nacional de Pró-reitores de Assuntos Comunitários e Estudantis (FONAPRACE) e da Associação Nacional dos Dirigentes das Instituições Federais de Ensino Superior (ANDIFES), em 1987.

Após a Constituição Federal (CF) de 1988, concretizam-se conquistas importantes a partir das lutas. A CF/88 incorporou reivindicações da sociedade civil expressas como direitos sociais previstos no artigo sexto "a educação, a saúde, a alimentação, o trabalho, a moradia, o transporte, o lazer, a segurança, a previdência social, a proteção à maternidade e à infância, a assistência aos desamparados" (BRASIL, 1991).

Com relação ao Ensino Superior, a Constituição de 1988 consagrou a falaciosa autonomia universitária, na realidade trata-se de uma autonomia relativa, pois com a precarização do ensino superior e a redução das verbas da educação pública, não há o que se falar de autonomia. Estabeleceu ainda a indissociabilidade entre ensino pesquisa e extensão, a gratuidade nos estabelecimentos oficiais e assegurou o ingresso por concurso público e o regime jurídico único.

Peroni (2003) destaca que a partir da década de 1990, as políticas de educação passam a sofrer forte influência da redefinição do papel do Estado e são, também, partes constitutivas 
das mudanças. Barroso (2005), em consonância com Peroni (2003), ressalta que o contexto histórico de ascensão da ideologia neoliberal, de desresponsabilização do Estado pelas políticas sociais tem impactado diretamente a educação que tem sido transformada em mercadoria e propõe como saída a reflexão sobre o verdadeiro papel da escola pública, que deve ter como objetivo a luta por justiça social e redução das desigualdades, rompendo com a lógica capitalista.

As legislações com previsões acerca da $A E$ se constituíram historicamente para atendimento parcial da pauta estudantil como uma forma de conter as reivindicações e mobilizações do movimento estudantil, contudo nunca com atendimento integral às necessidades dos estudantes, como mostra o estudo de Felippe e Silva (2018).

Mancebo, Silva Junior e Schugurensky (2016), ao analisarem o impacto da mundialização do capital na Educação Superior brasileira, ressaltam que inicialmente o impacto tem como ponto mais alto o ano de 1995, quando o Ministério da Administração Federal e da Reforma do Estado (MARE) elabora o Plano Diretor da Reforma do Estado (PDRE) sob a responsabilidade do ministro Luís Carlos Bresser Pereira.

Contudo, a reforma do Estado não ficou apenas no âmbito da economia com a privatização de estatais. No âmbito educacional, o foco estava na gestão. Com a promulgação, em 1996, da Lei de Diretrizes e Bases da Educação Nacional (LDBEN), houve maior flexibilização da oferta da Educação Superior para a iniciativa privada. Em seu Art. 7ㅇ, a LDBEN (BRASIL, 1996) determina que "o ensino é livre à iniciativa privada", abrindo espaço para uma reestruturação da Educação Superior no Brasil uma vez que autoriza claramente o funcionamento de instituições com fins lucrativos.

Em seu plano de reforma, Bresser Pereira identificou quatro setores no interior do Estado: o núcleo estratégico, as atividades exclusivas, os serviços não exclusivos ou competitivos e, por fim, a produção de bens e serviços para o mercado e, seguindo esse raciocínio, ele assevera que os serviços não exclusivos da União mais importantes são as universidades, as escolas técnicas, os centros de pesquisa, hospitais e museus, serviços esses que com a reforma, pretendia transformar em Organizações Sociais (OS) através do Programa de Publicização, uma espécie de entidade não estatal ou fundação pública de direito privado controlada por contrato de gestão celebrado com o executivo e que teria a permissão do congresso para participar do orçamento estatal (SILVA JÚNIOR; SGUISSARDI, 2001). 
Considerando as universidades e as escolas técnicas como parte dos serviços não exclusivos do Estado, dá-se início à reforma da Educação Superior brasileira com a reforma estatal em 1995. O principal projeto para o sistema de educação é o de descentralização dos serviços sociais, pois, desresponsabiliza gerencial e financeiramente o Estado de uma considerável parcela do sistema de ensino público, com efeitos negativos no sistema educacional, uma vez que transfere os serviços educacionais para os demais entes federados, mas não garante uma infraestrutura aos Estados e municípios, deixando a cargo destes, toda responsabilização pela precariedade da Educação.

Para Mancebo, Silva Júnior e Schugurensky (2016), o impacto mais perceptível da mundialização do capital na Educação Superior brasileira é mais evidente nos mandatos de Fernando Henrique Cardoso (FHC) e o início do primeiro mandato do governo Lula da Silva (2003/2007). Fase marcada pela edição de legislações decorrentes do Plano Diretor da Reforma do Estado com impacto nas Instituições de Ensino Superior (IES).

Os traços que passam a ser perseguidos, de um modo bem geral, na educação superior brasileira são: a pesquisa aplicada; cursos mais rápidos, inclusive apoiados em novas tecnologias de informação e comunicação; processos avaliativos ou de regulação calcados em resultados, entre outros. (MANCEBO; SILVA JUNIOR; SCHUGURENSK, 2016, p. 210)

Somado a isso há a perda da autonomia universitária influenciada pela "heteronomia de gestão", além da nova relação entre a universidade e o setor privado. Os impactos dessas ações são o sucateamento e desvalorização das universidades públicas, consequências do contingenciamento de recursos de custeio e capital, suspensão de concurso público para contratação de docentes e funcionários administrativos e, por fim, o congelamento dos salários, realidade até os dias atuais das universidades brasileiras.

Apesar disso, como resultado do histórico de reivindicações, a $A E$ passou a ser elencada pelo Plano Nacional de Educação (PNE) de 2001, no artigo no 33 e 34, nos quais tem previsão que a política pública de educação deverá prevê como meta para a Educação, o estímulo à adoção de programas de assistência estudantil como bolsa-trabalho ou outros destinados apoiar os estudantes carentes que demonstrem bom desempenho acadêmico em universidades públicas.

Em face desse cenário macro, o destaque do governo Lula (2003-2007) é a tentativa de se configurar como um governo de conciliação de classes, com programas sociais 
destinados a população em situação de vulnerabilidade como programa Bolsa-família, que ganhou visibilidade internacional; programas de construção de moradias populares, regulamentação da assistência estudantil nas universidades, concomitante a isso, houve grande destinação de recursos para o grande empresariado, especialmente, nas políticas de expansão do ES. Esse governo não rompe com o modelo econômico vigente.

Santiago (2014) assevera que a questão do acesso ao Ensino Superior na perspectiva da democratização e não massificação era uma reivindicação da sociedade, além da luta pelo direito à permanência, pois, já era evidente o grau de evasão na educação superior. Com a continuidade da privatização da Educação Superior, o presidente Lula atua por meio da Medida Provisória no 213, de 10 de setembro de 2004, que institui o Programa Universidade para Todos (PROUNI) no qual destacamos dois pontos estratégicos: 1이 atende ao setor privado; e 2ㅇ) aparenta atendimento das reivindicações das entidades estudantis por expansão e democratização do Ensino Superior.

Mancebo, Silva Júnior e Schugurensky (2016) destacam que o primeiro mandato do presidente Lula da Silva e em parte do governo de Dilma Rousseff é um período que tem como principal característica a emergência de programas com forte potencial de mudança institucional e a expansão da educação superior. Soma-se ao PROUNI, o Programa de Apoio ao Plano de Reestruturação e Expansão das Universidades Federais (REUNI), o incremento à educação a distância (EaD) e ao Fundo de Financiamento Estudantil (FIES).

\subsection{TERCEIRA FASE DA ASSISTÊNCIA ESTUDANTIL NO BRASIL}

A partir de 2007 inicia-se a terceira fase da AE. É o período do segundo mandato do Presidente Luís Inácio Lula da Silva (2007-2010). No âmbito da Educação Superior, o ano de 2007 é marcado pela Portaria Normativa no 39, de 12 de dezembro de 2007, que institui o Programa Nacional de Assistência Estudantil (PNAES), marco da AE.

Em todo percurso da ES e, consequentemente, da $A E$ é possível perceber fortes repercussões do ideário neoliberal, a exemplo das privatizações, foco dos governos de Collor de Melo e de Fernando Henrique Cardoso, já os governos petistas de Lula e Dilma a continuidade ao atendimento fiel do receituário neoliberal com a chamada "democratização do Ensino Superior", com novas formas de atendimento às demandas do mercado financeiro. 
Silva Júnior (2006) ressalta que o novo desenho da Educação Superior no Brasil apresenta uma universidade que se transformou rapidamente em organização e passou a oferecer produtos educacionais em resposta às demandas do capital, portanto, além do seu objetivo inicial de produção de conhecimento, extensão e prestação de serviços agrega a necessidade de apresentar a educação como uma mercadoria.

Apesar do viés de "conciliação de classes", com baixa visibilidade dos movimentos sociais, no governo Lula, em 2009, o quinquagésimo primeiro Congresso da União Nacional dos Estudantes (Conune), realizado em Brasília, discutiu como proposições a melhoria da educação pública, permanência estudantil, indissociabilidade entre ensino, pesquisa e extensão. Dentre as resoluções aprovadas no evento estava a criação de um Plano Nacional de Assistência Estudantil que garantisse ao estudante em situação de vulnerabilidade social, acesso à alimentação, transporte e material didático. Defendia ainda a criação de PróReitorias de Assistência Estudantil em todas as IFES públicas e verbas específicas para esse fim (UNE, 2018).

Nesse contexto, as políticas sociais de expansão do ES, marca do governo Lula, são divididas em dois grupos: aquelas do âmbito privado e aquelas do âmbito público. Ambas evidenciam claramente o processo de transformação de um direito em mercadoria, uma vez que as políticas sociais do Estado, não são independentes, recebem influências do mercado.

Destacamos como políticas de expansão do ES no âmbito privado o Fundo de Financiamento Estudantil do Ensino Superior (FIES) e o Programa Universidade para Todos (PROUNI). Trata-se de uma nova concepção de educação orientada não como um direito social, mas como um serviço, portanto, regulada pelas leis do mercado.

O FIES foi instituído pela Lei no 10.260, de 12 de julho de 2001; é destinado ao financiamento a "estudantes de cursos superiores não gratuitos". Ressaltamos que se trata de política focal, sem garantias de condições de permanência e nem mesmo de posterior sucesso no mercado de trabalho.

O Programa Universidade para Todos (PROUNI) foi criado em 2004, pela Lei $\mathrm{n}$ ㅇ 11.096/2005, e prevê como finalidade a "concessão" de "bolsas de estudos integrais e parciais a estudantes de cursos de graduação e de cursos sequenciais de formação específica, em instituições privadas de educação superior", sendo que as instituições que aderem ao programa recebem isenção de tributos. 
Sguissardi (2015, p. 869) salienta que a política de expansão da ES no Brasil, especialmente através de programas como o PROUNI e o FIES é uma política pública de caráter focal e compensatória das desigualdades sociais produzidas pelo modelo de desenvolvimento capitalista, "uma educação de elite e de alta qualidade" para poucos e uma educação de massa e de "baixa qualidade para muitos". Podemos inferir que nessa conjuntura, a expansão acelerada da iniciativa privada foi o resultado mais evidente do conjunto de reformas implantadas no ES.

Ao questionar se há democratização ou massificação mercantil na Educação Superior, o autor alerta para três pontos importantes: examinar como se têm dado o acesso à educação superior, a permanência até o final dos estudos e o sucesso ou insucesso dos titulados no mercado de trabalho. Vê-se que tais políticas atendem rigorosamente ao receituário neoliberal e beneficiam as grandes empresas, além de disseminar a falsa ideia da democratização do ES, quando se trata de um processo de expansão do ES marcado pela massificação mercantil.

As políticas de expansão do ES no âmbito público ganham ênfase com o Programa de Apoio aos Planos de Reestruturação e Expansão das Universidades Federais (REUNI) e Sistema Unificado de Seleção (SISU) uma vez que no Brasil as políticas públicas estatais de inclusão dos jovens das classes populares na Educação Superior estiveram direcionadas para o financiamento dessa modalidade de ensino em instituições privadas, fosse pela compra de vagas por meio do PROUNI ou via programas de crédito educativo.

O Programa de Apoio a Planos de Reestruturação e Expansão das Universidades Federais (REUNI) foi instituído pelo Decreto no 6.096, de 24 de abril de 2007. Segundo dados da Andifes (2011), no período do Reuni, destaca-se a ampliação da oferta de vagas nos cursos noturnos que foi de $79 \%$ e nas licenciaturas que representou aproximadamente $34 \%$. 0 Programa apresenta como objetivo "[...] criar condições para a ampliação do acesso e permanência na educação superior, no nível de graduação, pelo melhor aproveitamento da estrutura física e de recursos humanos existentes nas universidades federais" (BRASIL, 2007). O fato de ter sido um programa de governo estabelecido por um decreto e não uma lei já o tornou vulnerável, pois, em possível mudança de governo em 2010, não havia qualquer garantia de continuidade. Além disso, o Programa não foi pensado levando em conta o 
aparelhamento das universidades já existentes e nem contratação de novos docentes e servidores técnicos.

A Lei no 9.394, de 1996 e o Plano Nacional de Educação (PNE) 2001-2010, fundamentou o Reuni, estabeleceu provimento da oferta de Educação Superior para, pelo menos, 30\% dos jovens na faixa etária de 18 a 24 anos, até o final da década (BRASIL, 2010). No entanto, o REUNI não resolveu a questão da precarização da universidade pública; ao contrário, acentuou. O aumento das vagas nas IES desconsiderou a necessidade de planejamento adequado e a discussão com a comunidade acadêmica e demais interessados, como o movimento estudantil, docentes, gestores e sociedade civil, etc.

Do ponto de vista quantitativo houve expansão de cursos e ampliação da estrutura física, o que resultou no aumento do número de universidades e campi, como comprovam os resultados apresentados em 2012, a partir dos dados quantitativos do Reuni, resultado de um trabalho realizado por uma comissão instituída pelas Portarias no 126, de 2012 e no 148, de 2012, composta por representantes da Andifes, Secretaria de Educação Superior (Sisu/MEC), União Nacional dos Estudantes e pela Associação Nacional de Pós-Graduandos (ANPG).

Em atendimento aos ditames do capital, especialmente dos organismos internacionais, de redução de gastos por aluno, o governo brasileiro passou a desenvolver mecanismos de avaliação da qualidade do ensino, com criação de novas modalidades de acesso e concorrência para ingresso no ES público. Uma das medidas foi a criação do Sistema de Seleção Unificada (SISU). Trata-se de um sistema informatizado do MEC no qual instituições públicas de Ensino Superior ofertam vagas para participantes do Exame Nacional do Ensino Médio (Enem). Nessa modalidade de seleção, o candidato deve escolher, por ordem de preferência, até duas opções entre as vagas ofertadas pelas instituições participantes do SISU. O candidato também opta por vagas destinadas às políticas afirmativas das instituições. A adesão ao SISU vem ocorrendo de maneira gradativa tanto nas universidades federais quanto nas estaduais. Sua utilização ocorre em conjunto com outras formas de ingresso para, futuramente, tornar-se o meio de acesso universal.

A ideia do SISU tem diversas implicações positivas, mas também aspectos que demonstram a prevalência do critério meritocrático, além disso, não houve investimento nas universidades públicas, nem em pessoal, nem em infraestrutura. O SISU promove a participação nos processos seletivos para o Ensino Superior público, pois, torna possível aos 
candidatos concorrer a todos os cursos cadastrados no sistema, sem custos financeiros, o que possibilita maior participação de grupos de camadas populares.

Como forma de resistência às políticas de massificação, houve mobilização de oposição às reformas do governo FHC e do governo Lula por parte de instituições como o Sindicato Nacional dos Docentes das Instituições de Ensino Superior (ANDES), a Associação Nacional dos Dirigentes das Instituições Federais de Ensino Superior (ANDIFES) e a Federação de Sindicatos de Trabalhadores Técnico-Administrativos em Instituições de Ensino Superior Públicas do Brasil (FASUBRA), entre outras, com objetivo de garantir a valorização das universidades federais, demonstrando que os dados oficiais publicados de expansão não levavam em conta questões mais complexas.

É inegável o impacto positivo das políticas públicas de expansão de matrículas e de inclusão social, as quais se constituem um passo importante para superação das desigualdades. No caso dos jovens das classes pobres, mas também para o país de modo geral, “[...] a expansão das matrículas apresenta um alto valor" (DIAS SOBRINHO, 2010, p. 1.238). Para esses jovens que, além da vulnerabilidade econômica, em geral chegam ao nível superior com baixos repertórios educacionais e culturais, cada ano de escolaridade pode significar ganhos salariais, aumento no padrão de consumo, elevação da autoestima e das possibilidades de alcançarem melhores posições sociais.

Isso pode significar também um grande número de estudantes que migra de suas cidades para estudar em centros universitários, muitas vezes, sem ter garantidas as condições de permanência da graduação. Portanto, tal expansão é contraditória; de um lado possibilita o acesso ao Ensino Superior, de outro desconsidera que apenas o acesso não garante a conclusão da graduação. Haja vista que a questão da universalização dos processos seletivos para ingresso nas universidades públicas não foi pensada juntamente com outras questões importantes, como as políticas de permanência dos estudantes e desempenho acadêmico daqueles oriundos de camadas populares.

Essa situação foi agravada a partir do golpe político de 2016, quando o governo Temer dá continuidade à mesma tônica dos governos anteriores; aumentando as desigualdades e o desmantelamento de direitos sociais conquistados a duras penas. No campo da educação o Estado é reduzido ainda mais, com um projeto de governo denominado "Ponte para o Futuro". As propostas para este campo aprofundam o sucateamento do ensino público com baixo 
investimento em pesquisa e defesa de uma educação sem criticidade, a exemplo do projeto de reforma do Ensino Médio (Lei no 13.415, de 2017) que abriu espaço para o controverso Projeto Escola Sem Partido (Projeto de Lei no 867, de 2015), além do congelamento dos gastos na área da Educação por duas décadas com a Emenda Constitucional no 95/2016, conhecida como PEC da Maldade. A redução das verbas impacta diretamente a política de permanência, com impacto direto no cotidiano das universidades.

A breve exposição realizada até aqui serve de parâmetro para evidenciar a influência que a reestruturação produtiva e o ideário neoliberal tiveram no campo educacional brasileiro tanto nos governos FHC quanto nos governos Lula, Dilma e Temer. O que sobressai ao longo das últimas décadas é o esforço com objetivo de uma expansão quantitativa, não importando muito se essa expansão se dá como usufruto de um direito público ou se apenas como compra de um serviço, produto comercial ou mercadoria (SGUISSARDI, 2015).

Para melhor compreensão da AE faz-se necessário conhecer a legislação que influenciou o desenvolvimento das políticas de permanência na Educação Superior Brasileira. Neste sentido, o Programa Nacional de Assistência Estudantil (PNAES) instituído em 12 de dezembro de 2007, pela Portaria Normativa no 39 do MEC e o Decreto no 7.234 de 2010, constitui o marco legislativo.

A Assistência Estudantil, oficializada através do PNAES, é fruto de uma luta histórica da UNE, da Secretaria Nacional de Casa de Estudantes (SENCE) e do FONAPRACE. Com um passado recente de ações fragmentadas nas universidades, como nos anos 1990, passa a ser orientada em legislação específica. No entanto, a AE persiste com visíveis influências do contexto macro, como atendimento ao receituário neoliberal. Catani e Oliveira (2002, p. 75) destacam que o Banco Mundial (BM) possui algumas orientações para o processo de reestruturação das universidades públicas dentre estas, a diversificação das fontes de financiamento das instituições estatais, bem como a adoção de incentivos para o seu desempenho. A mobilização dos fundos privados para o ES, “[...] especialmente através da participação dos estudantes nos gastos, dos egressos, da ajuda externa de organismos de financiamento, da ampliação dos serviços". Ainda conforme Catani e Oliveira (2002, p. 75), também faz parte destas orientações do BM, “[...] o atendimento e apoio aos estudantes pobres, mas qualificados, através de planos/programas de assistência; melhorar a dotação e 
a utilização de recursos entre e dentro das instituições", sobretudo, através da vinculação do financiamento a critérios de desempenho institucional.

Para atender a essas orientações e, ao mesmo tempo, atender às reivindicações das IFES e dos movimentos estudantis, especificamente da UNE, FONAPRACE e ANDIFES, o Governo Federal passou a destinar recursos específicos para AE. Como resultado das lutas das entidades supracitadas, a AE ganha status de política pública, passando a ser regida pelo Decreto 7.234 de 19 de julho de 2010; é o reconhecimento de sua importância para ampliar as condições de permanência dos jovens em situação de vulnerabilidade social na Educação Superior pública.

O citado Decreto estabelece também que as ações de AE sejam desenvolvidas nas áreas de moradia estudantil, alimentação, transporte, atenção à saúde, inclusão digital, cultura, esporte, creche, apoio pedagógico e acesso, participação e aprendizagem de estudantes com deficiência, transtornos globais do desenvolvimento e altas habilidades e superdotação (BRASIL, 2010).

A AE está inserida na política pública de educação e se configura como uma política focalizada, elencada na CF/1988 como um direito social. Uma das suas contradições se dá com dicotomia de política focalizada e política universal. Políticas focais como aquelas que se destinam a parcelas da população trabalhadora ou excluída e têm alcance limitado, já que não atuam sobre as causas da desigualdade social causadora da exclusão. Por seu turno, as políticas sociais são denominadas de universais quando atuam sobre aspectos estruturais do sistema econômico-político, como aumento real e constante do salário mínimo ou para eliminar as causas do desemprego e da exclusão social.

$A$ articulação da $A E$ na tríade ensino-pesquisa-extensão, garantida como práxis acadêmica e direito social, foge a lógica da política focal, desse modo, com superação do caráter minimalista e assistencialista das políticas sociais. Isso ficou evidente com as discussões propostas pela UNE em 2013:

Parte do princípio que as Políticas de Assistência Estudantil devem ser vistas como um direito social e como a garantia política de cidadania e dignidade humana. Para tanto deve estar inserida na práxis acadêmica com ações articuladas com o ensino, pesquisa e extensão. (Site UNE, 2018) 
Na prática, a materialização da $A E$ não se dá com esta dimensão de universalização. Imersa na realidade de redução dos recursos, na lógica do Estado-mínimo, se efetiva, de fato voltada para atendimento das necessidades mínimas de sobrevivência. Behring (2009) destaca que a política social atende às necessidades do capital e do trabalho, configurandose, já que para muitos se trata de uma questão de sobrevivência, como um cenário importante da luta de classes em defesa de condições dignas de existência.

\section{CONSIDERAÇÕES FINAIS}

A Assistência Estudantil tem suas bases firmadas na contradição, podendo assumir um caráter de concretização de direitos, como também de atendimento aos ditames do neoliberalismo e a lógica da manutenção das desigualdades sociais como ocorre na atualidade. A conformação da AE está fortemente ligada às transformações sociopolíticas do país e aos seus impactos na história da Educação Superior brasileira, de sua trajetória até ganhar maior legitimidade na agenda do governo e alcançar o status de política pública nos anos 2000.

A compreensão da totalidade nessa análise se deu com o aprofundamento acerca do receituário neoliberal para a Educação Superior no Brasil e suas consequências como a reforma do Estado no Governo FHC e com os governos de conciliação de classes Lula e Dilma, os quais deram continuidade à mercantilização do Ensino Superior e imprimiram a massificação do ES erroneamente divulgada como democratização.

A AE se apresenta ao longo de todas as suas fases, como uma política focal, imersa na lógica da redução do papel do Estado nas políticas públicas e com atendimento parcial das reivindicações do movimento estudantil, importante ator na luta por uma política de permanência estudantil universal.

\section{REFERÊNCIAS}

ANTUNES, Ricardo; RIDENTE, Marcelo. Operários e estudantes contra a ditadura: 1968 no Brasil. Mediações, Londrina, v. 12, n. 2, p.78-89, jul./dez. 2007. DOI: 10.5433/21766665.2007v12n2p78. Disponível em: http://www.uel.br/revistas/uel/index.php/mediacoes/article/view/3319/2719. Acesso em: 20 mai. 2018. 
BARBOSA, Lia Pinheiro; ROSSET, Peter Michael. Movimentos Sociais e Educação do Campo na América Latina: aprendizagens de um percurso histórico. Revista Práxis Educacional, Vitória da Conquista, v.13, n. 26, set./dez. 2017. Disponível em: http://periodicos2.uesb.br/index.php/praxis/article/view/2819. Acesso em: 10 set. 2019.

BARROSO, João. O Estado, a educação e a regulação das políticas. Educação e Sociedade, Campinas, v. 26, n. 92, p. 725-751, out. 2005. Disponível em: http://www.scielo.br/pdf/es/v26n92/v26n92a02.pdf. Acesso em: 20 mai. 2018.

BEHRING. Elaine Rossetti. Política Social no contexto da crise capitalista. In: BEHRING, Elaine Rossetti Rossetti; BOSCHETTI, Ivanete (Org.). Serviço Social: direitos profissionais e competências profissionais. Brasília: CFESS/ABEPSS, 2009. p. 301-322.

BRASIL. Constituição da República Federativa do Brasil (1988). São Paulo: Saraiva, 1991.

BRASIL. Decreto no 6.096, de 24 de abril de 2007. Programa de Apoio a Planos de Reestruturação e Expansão das Universidades Federais. Diário Oficial da União, Brasília, DF, 25 de abril de 2007. Seção 1, 206 p. 7. Disponível em: http://www.planalto.gov.br/ccivil_03/_ato2007-2010/2007/decreto/d6096.htm. Acesso em: 20 mai. 2018.

BRASIL. Decreto no 7.234, de 19 de julho de 2010. Programa Nacional de Assistência Estudantil. Diário Oficial da União, Brasília, DF, 19 jul. 2010. Disponível em: http://www.planalto.gov.br/ccivil_03/_ato2007-2010/2010/decreto/d7234.htm. Acesso em 20: maio. 2018.

BRASIL. Lei no 9.394, de 20 de dezembro de 1996. Diretrizes e Bases da Educação Nacional. Diário Oficial da União, Brasília, DF, 20 dez. 1996. Disponível em:

http://www.planalto.gov.br/ccivil_03/leis/19394.htm. Acesso em: 30 jan. 2018.

BRITO, Regivane dos Santos; PRADO, Jany Rodrigues; NUNES, Claudio Pinto. As condições de trabalho docente e o pós-estado de bem-estar social. Revista Tempos e Espaços em Educação (online), v. 10, p. 165-174, 2017. Disponível em: https://seer.ufs.br/index.php/revtee/article/view/6676. Acesso em: 21 ago. 2019.

CASTRO NETA, Abília Ana de; CARDOSO, Berta Leni Costa, NUNES, Claudio Pinto. Reformas educacionais no contexto pós-golpe de 2016. Revista Educação em Debate, Fortaleza, v. 40, p. 162-174, 2018. Disponível em:

http://www.periodicosfaced.ufc.br/index.php/educacaoemdebate/article/view/703. Acesso em: 20 ago. 2019.

CATANI, Afrânio Mendes; OLIVEIRA, João Ferreira de. A educação superior. In: OLIVEIRA, Romualdo Portela de; ADRIÃO, Theresa (Orgs.). Organização do ensino no Brasil: níveis e modalidades na Constituição Federal e na LDB. São Paulo: Xamã. 2002. p. 77-88. 
COSTA, Ana Sheila Fernandes; AKKARI, Abdeljalil; SILVA, Rossana Valéria Souza. Educação básica no Brasil: políticas públicas e qualidade. Revista Práxis Educacional, Vitória da Conquista, v.7, n. 11, jun./dez. 2011. Disponível em:

http://periodicos2.uesb.br/index.php/praxis/article/view/666. Acesso em: 14 set. 2019.

DIAS SOBRINHO, José. Democratização, qualidade e crise da educação superior: faces da exclusão e limites da inclusão. Educação e Sociedade, Campinas, v. 31, n. 113, p. 1223-1245, 2010. DOI 10.1590/S0101-73302010000400010. Disponível em:

http://www.scielo.br/pdf/es/v31n113/10.pdf. Acesso em: 20 mai. 2018.

DUARTE, Alexandre William Barbosa; OLIVEIRA, Dalila Andrade. Valorização profissional docente nos sistemas de ensino de Minas Gerais e Pernambuco. Revista Práxis Educacional, Vitória da Conquista, v.10, n. 17, jun./dez. 2014. Disponível em:

http://periodicos2.uesb.br/index.php/praxis/article/view/780. Acesso em: 14 set. 2019.

FELIPPE, Jonis Malhães Sales; Silva, Renata Maldonado da. Orçamento da assistência estudantil: análise a partir da experiência do Instituto Federal Fluminense campus CamposCentro. Revista Tempos e Espaços em Educação, v. 11, n. 25, p. 97-110, 2018.

DOI: 10.20952/revtee.v11i25.6755. Disponível em:

https://seer.ufs.br/index.php/revtee/article/view/6755/pdf. Acesso em: 20 mai. 2018.

FREIRA, Maria Auxiliadora S. Práxis pedagógica e professores intelectuais: refletindo as tensões e concepções da formação/prática docente. Revista Práxis Educacional, Vitória da Conquista, v.1, n. 1, jan./dez. 2005. Disponível em:

http://periodicos2.uesb.br/index.php/praxis/article/view/485. Acesso em: 17 set. 2019.

FREITAS NETO, José Alves de. A reforma universitária de Córdoba (1918): um manifesto por uma universidade latino-americana. Revista Ensino Superior Unicamp, v. 3, p. 62-73. 2011. Disponível em:

http://www.gr.unicamp.br/ceav/revistaensinosuperior/ed03_junho2011/pdf/10.pdf. Acesso em: 20 mai. 2018.

FRIGOTTO, Gaudêncio. Educação e a crise do capitalismo real. São Paulo: Cortez, 2010.

ILHA, Franciele Roos da Silva; HYPOLITO, Álvaro Moreira. O trabalho docente no início da carreira e sua contribuição para o desenvolvimento profissional do professor. Revista Práxis Educacional, Vitória da Conquista, v.10, n. 17, jun./dez. 2014. Disponível em:

http://periodicos2.uesb.br/index.php/praxis/article/view/781. Acesso em: 1 set. 2019.

KOWALSKI, Aline Viero. Os (des)caminhos da política de assistência estudantil e o desafio na garantia de direitos. 2012. 180 p. Tese (Doutorado em Serviço Social) - Faculdade de Serviço Social, Pontifícia Universidade Católica do Rio Grande do Sul, Porto Alegre, 2012.

MANCEBO, Deise; SILVA JÚNIOR, João dos Reis; SCHUGURENSKY, Daniel. A educação superior no Brasil diante da mundialização do capital. Educação em Revista, Belo Horizonte, v. 32, n. 4, p. 205-225, 2016. 
MARX, Karl; ENGELS, Friedrich. Manifesto do Partido Comunista. São Paulo: Expressão Popular, 2011.

MOTTA, Vânia Cardoso da. Gerar capital social: tarefa da educação periférica segundo Banco Mundial. Anais do VI Seminário do Trabalho, Economia e Educação. Marília, 2008.

Disponível em:

http://www.estudosdotrabalho.org/anais6seminariodotrabalho/vaniacardosodamotta.pdf. Acesso em: 02/01/2018.

NASCIMENTO, L. F.; CAVALCANTE, M. M. D. Abordagem quantitativa na pesquisa em educação: investigações no cotidiano escolar. Revista Tempos e Espaços em Educação, v. 11, n. 25, p. 249-260, 29 mar. 2018. Disponível em:

https://seer.ufs.br/index.php/revtee/article/view/7075 Doi:

https://doi.org/10.20952/revtee.v11i25.7075

NETTO, José Paulo. Capitalismo monopolista e serviço social. São Paulo: Cortez, 2011.

NETTO, José Paulo. Crise do capital e consequências societárias. Serviço Social e Sociedade, São Paulo, n.111, p. 413-429, 2012.

NUNES, Claudio Pinto. Formación y trabajo docente: cuestiones contemporáneas. Êxitus, Santarém, v. 9, n. 1, 2019. Disponível em:

http://www.ufopa.edu.br/portaldeperiodicos/index.php/revistaexitus/article/view/917. Acesso em: 29 ago. 2019.

NUNES, Claudio Pinto; OLIVEIRA, Dalila Andrade. Trabalho, carreira, desenvolvimento docente e mudança na prática educativa. Educação e Pesquisa, São Paulo, v. 43, p. 65-80, 2017. Disponível em: https://www.scielo.br/scielo.php?pid=S1517-

97022017000100066\&script=sci abstract\&tlng=pt. Acesso em: 18 ago. 2019.

PARASKEVA, J. M. "Brutti, Sporchi \& Cattivi": Towards a Non-Abyssal Curriculum. Revista Tempos e Espaços em Educação, v. 9, n. 18, p. 75-90, 2016. Disponível em:

https://seer.ufs.br/index.php/revtee/article/view/4966 Doi:

https://doi.org/10.20952/revtee.v9i18.4966

PEREZ, Marcia Cristina Argenti. Infância e escolarização: discutindo a relação família, escola e as especificidades da infância na escola. Revista Práxis Educacional, Vitória da Conquista, v. 8, n. 12, jan./jun. 2012. Disponível em:

http://periodicos2.uesb.br/index.php/praxis/article/view/684. Acesso em: 15 set. 2019.

PERONI, Vera Maria Vidal. Política educacional e papel do Estado no Brasil dos anos 90. São Paulo: Xamã, 2003. 
RIBEIRO, Júlia Cecília de Oliveira Alves; SILVA, Daniela Oliveira Vidal da; CARDOSO, Elisângela Andrade Moreira; NUNES, Claudio Pinto. A educação do campo em tempos de privatização e golpe. Revista Cenas Educacionais, Caetité, v. 1, p. 111-128, 2018. Disponível em:

https://www.revistas.uneb.br/index.php/cenaseducacionais/article/view/5141. Acesso em: 22 ago. 2019.

SANTIAGO, Salomão Nunes. A Política de Assistência Estudantil no governo Lula: 2003 a 2010. 238 p. Dissertação (Mestrado em Educação) - Universidade Federal do Pará, Belém, 2014.

SAVIANI, Dermeval. A expansão do ensino superior no Brasil: mudanças e continuidades. Poíesis Pedagógica, v. 8, n. 2, p. 4-17, 2010. Disponível em: https://www.revistas.ufg.br/poiesis/article/view/14035/8876. Acesso em: 20 mai. 2018.

SENCE, Secretaria Nacional de Casas de Estudantes: Base de Dados. Disponível em: http://sencebrasil.blogspot.com/p/sobre-sence.html. Acesso em: 25 mar. 2018.

SILVA, Daniela Oliveira Vidal da; BRITO, Vera Lúcia Fernandes de; NUNES, Claudio Pinto. Valorização docente na conjuntura do pós impeachement de 2016 no Brasil. Revista Cocar (online), v. 13, p. 1-20, maio/ago. 2019. Disponível em:

https://periodicos.uepa.br/index.php/cocar/article/view/2518. Acesso em: 07 nov. 2019.

SILVA, Nilson Robson Guedes. Gestão escolar democrática: uma contextualização do tema. Revista Práxis Educacional, Vitória da Conquista, v. 5, n. 6, jan./jun. 2009. Disponível em: http://periodicos2.uesb.br/index.php/praxis/article/view/590. Acesso em: 13 ago. 2019.

SGUISSARDI, Valdemar. Educação Superior no Brasil. Democratização ou massificação mercantil? Educação e Sociedade Campinas, v. 36, n. 133, p. 867-889, dez. 2015. DOI: 10.1590/ES0101-73302015155688. Disponível em:

http://www.scielo.br/pdf/es/v36n133/1678-4626-es-36-133-00867.pdf. Acesso em: 20 mai. 2018.

SILVA JÚNIOR, João dos Reis; SGUISSARDI, Valdemar. Novas Faces da educação Superior no Brasil: reforma do Estado e mudanças na produção. São Paulo: Cortez. 2001.

SILVA JÚNIOR, João dos Reis. Universidade e mundo do trabalho: aproximações para uma discussão. In: MOLL, Jaqueline; PALMIRA, Sevegnani. Universidade e mundo do trabalho. Brasília: Instituto Nacional de Estudos e Pesquisas Educacionais Anísio Teixeira, 2006.

UNIÃO NACIONAL DOS ESTUDANTES: Base de dados. Disponível em: http://une.org.br/memoria/. Acesso em: 22 jan. 2018.

VASCONCELOS, Natalia Batista. Programa nacional de assistência estudantil: uma análise da evolução da assistência estudantil ao longo da história da educação superior no Brasil.

Ensino Em Re-vista, v. 17, n. 2, p. 599-616, jul./dez. 2010. Disponível em: 
http://www.seer.ufu.br/index.php/emrevista/article/view/11361/6598. Acesso em: 20 mai. 2018.

\section{SOBRE AS AUTORAS:}

\section{Marília do Amparo Alves Gomes}

Mestre em Educação pela Universidade Estadual do Sudoeste da Bahia (UESB); Programa de Pós-Graduação em Educação PPGED/UESB; Membro do Grupo de Pesquisa em Ludicidade, Didática, Política e Práxis Educacional (LUDIPPE) e Grupo de Estudos e Pesquisas em Políticas para a Educação Superior (GEPPS).

E-mail: mariliaamparo@gmail.com

ORCID: https://orcid.org/0000-0002-2321-3813

\section{Ennia Débora Passos Braga Pires}

Doutora em Educação pela Universidade Estadual de Campinas (UNICAMP), Docente do Programa de Pós-Graduação em Educação PPGED da Universidade Estadual do Sudoeste da Bahia (UESB); Líder do Grupo de Pesquisa em Ludicidade, Didática, Política e Práxis Educacional (LUDIPPE).

Email: enniadebora@uesb.edu.br

ORCID: https://orcid.org/0000-0003-3924-4996

\section{Soane Santos Silva}

Mestre em Educação pela Universidade Estadual do Sudoeste da Bahia (UESB); Programa de Pós-Graduação em Educação PPGED/UESB; Docente da Rede Municipal de Educação do Município de Itapetinga, Bahia/Brasil; Membro do Grupo de Pesquisa em Ludicidade, Didática, Política e Práxis Educacional (LUDIPPE).

E-mail: soanesilva@hotmail.com

ORCID: https://orcid.org/0000-0003-3807-1798

Recebido em: 20/03/2020

Aprovado em: 23/04/2020

Publicado em: 27/04/2020 